\title{
Assessment of Salt status in the Moroccan population based on food frequency questionnaire \& 24-hour dietary recall
}

\author{
Anass Rami ${ }^{1,4}$, Amina Bouziani ${ }^{4}$, Mohamed Idrissi ${ }^{4}$, Arthur Georges Assako Akom ${ }^{4}$, Jahdiel Kossou ${ }^{2}$, \\ Mohammed El Mzibri ${ }^{4}$, Naima Safsaf ${ }^{4}$, Asmae El Hamdouchi ${ }^{4}$, Imane Menachawy Benjelloun ${ }^{3}$, Kaoutar \\ Benjeddou ${ }^{4}$, Khalid El Kari ${ }^{4}$, Naima Saeid ${ }^{4}$ and Hassan Aguenaou ${ }^{4}$. \\ ${ }^{1}$ Research Laboratory Innovation \& Information System, EuRSED Vienne France. \\ ${ }^{2}$ School of nutrition, Food sciences and Technologies, Faculty of agronomics Sciences, Abomey-Calavi, Republic of Benin \\ ${ }^{3}$ World Health Organization, Rabat, Morocco \\ ${ }^{4}$ Joint Research Unit in Nutrition; Health and Environment, RDC- Nutrition AFRA/IAEA, Laboratory Biology \& Health \\ (Ibn Tofaïl University - CNESTEN), Morocco
}

\begin{abstract}
Salt is an essential mineral to our health that, in its sodium form, is involved in many functional processes in human body. Excessive salt consumption increases the risk of high blood pressure and cardiovascular disease (CVD). The World Health Organization (WHO) and the United Nations (UN) have identified salt reduction as one of the most cost-effective strategies to prevent the spread of non-communicable diseases. The objectives of the present study is to determine the salt status in the Moroccan population based on 24-hour dietary recall and food frequency.

This descriptive cross-sectional study was conducted on 133 children and adolescents recruited from public schools in Rabat regions. The average total salt intake status was assessed by $24 \mathrm{~h}$ dietary recall. Food frequency questionnaire was used to evaluate children's nutritional habits and the consumption of food rich in salt.

The average total salt intake is $5264.5 \pm 2398.6 \mathrm{mg} /$ day. The knowledge of the study population on the health risks of excess salt, $81 \%$ of participants stated that high salt consumption is positively associated with health risks, while only $7 \%$ confirmed that there is no relationship between excess salt and health problems. For the use of iodized salt, about half $(46.6 \%)$ of the study population uses iodized salt. For each variable, a significant difference is shown between the subgroups $(p<0.001)$.

The current intake of salt is very high in both children and adults. Reducing salt intake is one of the most cost-effective measures to prevent CVD. A low-salt diet during childhood can prevent the development of CVD and hypertension later in life. However, there is no strategy to keep children and adults low in salt.
\end{abstract}

Key words: Salt, Children and adolescents, 24h Dietary recall, Morocco

\section{Introduction}

Salt is an essential mineral to our health in its sodium form, and is involved in many functions of the human body [1]. It is one of the ingredients that is universally used in cooking, and preservation of manufactured food around the world. It is present in most of our foods. In many processed foods, salt is excessively used [1]. However, in natural foods, salt is present in small amounts with a significant percentage in those of animal origin compared to those of plant ones [2].

This mineral was the most taxed and traded commodity in the world, with intake reaching a peak around the 19th century [3]. Its intake has increased with the advance of civilization. In addition, countries with high consumption of foods processed to a traditional diet rich in salt have a high salt intake [4].

Recently, salt has been the subject of numerous studies on salt consumption and the emergence of various health conditions because its excessive consumption has been shown to be one of the main risks for world health [5], has also confirmed by the World Health Organization (WHO). The latter has reported that overconsumption of salt is currently a public health objective that must be taken into consideration and which is part of his action plan for the prevention and control of non-communicable diseases (NCD) [6]. Indeed, the WHO has urged member countries to put in place strategies aimed at a 
$30 \%$ reduction in salt consumption among the general population in order to reduce the incidence of various NCDs and therefore the minimization of mortality rate [7-8]. Thus, a moderate reduction in dietary salt intake is an effective measure to prevent a range of pathologies. In this context, 32 salt reduction strategies have been identified around the world, which are systematically based on food reformulation, consumer awareness initiatives and labeling actions [9]. These initiatives have therefore shown their positive effect in a large-scale interventions package showing a significant reduction in the incidence of non-communicable diseases. As part of its recommendations to reduce salt consumption, this organization encourages the development of supportive environments to promote healthy food choices [10]. This would be achievable through the use of a clear, concise and consistent nutrition. Additionally, for adults, WHO recommends a salt intake of less than 5 grams per day presenting the optimum which could save around 1.7 million lives annually [11-12]. Concerning children aged 2 to 15 years old, the recommended intake for adults should be adjusted downwards according to their energy needs compared to those of adults [11].

Over the past century, the evidence for the risks to human health from excessive salt consumption has become convincing. The causal relationship between habitual dietary salt intake and blood pressure has been established by experimental, epidemiological and intervention studies [13]. Thus, it has been shown that this nutrient can cause different health disorders, such as osteoporosis, hypertension, asthma, gastric cancer and nephrolithiasis [14], which present the main cause of mortality in the world [15].

The Knowledge on the harmful effects of salt on health differs from one population to another around the world, as mainly has shown in different observational and clinical experimental studies [16, $11,17]$.

Internationally, various studies have been carried out for daily salt intake in the different continents showing an overconsumption of this ingredient [18, $19,20,21]$. Indeed, most people present an average intake of 9-12 g of salt per day according to WHO report [12].

However, in Morocco, the exact average amount of the total salt consumption and the good knowledge of the different effects of overconsumption of salt remains unknown. Nevertheless, considering the negative impact of excessive salt consumption on health and in particular on blood pressure levels and cardiovascular diseases, WHO-EMRO has

\footnotetext{
*Corresponding author: anass.rami@uit.ac.ma ; anassrami13@gmail.com
}

recommended a project of research to estimate the salt intake in Morocco [22]. Therefore, the aim of this study is to determine the salt status in the Moroccan population based on 24-hour dietary recall and food frequency.

\section{Materials and Methods}

In this cross-sectional study, 133 young Moroccan adults (aged from 8 to 19 years) were recruited from their school in Rabat region. The subjects were at normal weight, in good health, and had no physical or psychological health problems affecting their physical mobility, appetite, or food intake.

Primary and secondary schools directors were contacted via a phone call to request their school's participation in the study. Before starting the survey, a simple explanation was given to the participants to explain the objective and general design of this study, then information was given to parents or guardians in order to convince them to sign the consent of participation. The study was approved by The Ethical Committee Biomedical research of the Faculty of Medicine and Pharmacy, Rabat.

\section{Anthropometry characteristics}

Each participant anthropometric parameters were measured in the morning, in a reserved room by trained interviewers and following the WHO standardized procedures [23].

Body height was measured, barefoot and in a standing position, to the nearest of $0.1 \mathrm{~cm}$ using a calibrated stadiometer (formerly Shorr Productions, LLC, USA). For weight, the measurement was done to the nearest of $0.1 \mathrm{~kg}$ by a calibrated electronic scale (Seca $\mathrm{GmbH}$, Germany) provided that the participants are lightly dressed and without shoes.

\section{Dietary intake}

The details of dietary information were collected using three 24-hour dietary recalls that present an important method used for dietary assessment in large epidemiological studies [24, 25, 26, 27]. Indeed, details of food and drink consumption, preparation methods, and all portion sizes as consumed were collected among the participants by direct interviews. For each 24-hour intake collection, the interviewer asked subjects to recall successively all intakes of the previous day including snacks and water. These interviews were repeated 3 separate days over a period of between 20 and 30 minutes and over an interval not exceeding 15 days. The estimation of the various food 
portions and the precision of the quantities consumed were made using two manuals that group all foods, specifically Moroccan meals.

For children under 11, parents or guardians have been invited to participate in filling out the food questionnaire.

\section{Food frequency questionnaire}

Estimation of food frequency consumption was established using a validated questionnaire that includes a list of foods classified into a number of items. Thus, different foods eaten by the participant were registered and expressed by number of times per day, per week or per month [28]. For this study, it is the monthly frequency of the food consumption that has been reported. This questionnaire is one of the most common tools used in large-scale studies to examine the relation between diet and diseases apparition, owing to easy administration and low cost [29].

\begin{abstract}
Data analysis
Using Epi-info software (Version 7), data collected from the questionnaires was analyzed. For assessment of dietary intake, Nutrilog software (SAS, version: 2.31) was used to obtain details on macro and micronutrients intake and also general quantities of different consumed foods. The frequency of subjects in categorical variables was calculated using descriptive statistics. Chi-square analysis was used to determine significant relationships between categorical variables. A p-value of $<0.05$ was taken as significant.
\end{abstract}

\section{Results}

Subject Characteristics are presented in table 1. Our study population includes 65 girls and 68 boys. For all participants, the mean age was $10.1 \pm 2.5$ years and values of the BMI are included in a normal range with a mean of BMI-z-score for age $-0.1 \pm 1.6$. According to sex, there is no significant difference for all variables $(\mathrm{p}<0.05)$.

Table 1: Anthropometric results of the study population by sex

\begin{tabular}{lcccc}
\hline & Girls $(\mathbf{n}=\mathbf{6 5})$ & Boys $(\mathbf{n}=\mathbf{6 8})$ & Total $(\mathbf{n}=\mathbf{1 3 3})$ & p-value \\
\hline Age (years) & $10.4 \pm 2.6$ & $9.8 \pm 2.41$ & $10.1 \pm 2.5$ & 0.187 \\
Weight $(\mathbf{K g})$ & $34.0 \pm 12.1$ & $32.2 \pm 11.0$ & $33.1 \pm 11.5$ & 0.354 \\
Height $(\mathbf{c m})$ & $138.1 \pm 13.8$ & $137.0 \pm 14.4$ & $137.5 \pm 14.0$ & 0.634 \\
BMI (kg/m $\left.\mathbf{m}^{2}\right)$ & $17.3 \pm 3.5$ & $17.2 \pm 4.9$ & $17.3 \pm 4.3$ & 0.844 \\
BMI-for-age z-score & $-0.1 \pm 1.3$ & $-0.1 \pm 1.8$ & $-0.1 \pm 1.6$ & 0.800 \\
\hline
\end{tabular}

Results are presented as mean \pm standard deviation

General findings of nutritional and dietary intake are presented in table 2 and figure 1 . Results showed that the total mean of salt intake is $5264.5 \pm 2398.6$ $\mathrm{mg} /$ day. For daily food consumption, it appears that bread and its derivatives present the most contribution to salt intake, in children and adolescents diets, with a percentage of $40 \%$, followed by vegetables and fruits with 36\%. Whereas, Meat products consumption represents $11 \%$ whereas sauces and fish contribute, respectively, with just $7 \%$ and $3 \%$ of total daily consumption (figure1). Overall, data statistical analysis showed no significant difference between boys and girls. 
Table 2: Total dietary intake of the participants by sex

\begin{tabular}{lcccc}
\hline & Total & Boys & Girls & p-value \\
\hline Salt (mg/day) & $5264.5 \pm 2398.6$ & $5420.2 \pm 2747.1$ & $5101.6 \pm 1978.1$ & 0.446 \\
Sodium (mg/day) & $2065.4 \pm 940.8$ & $2133.9 \pm 1081.5$ & $1991.4 \pm 762.3$ & 0.338 \\
\hline
\end{tabular}

$P$-values by Epi-info for means; Results are presented as means

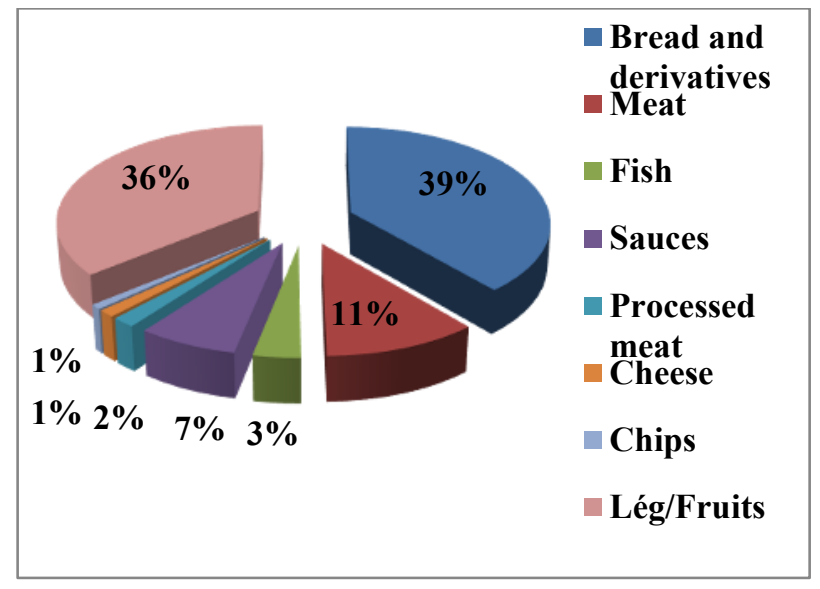

Figure 1: Percentage of contribution of commonly consumed food in salt intake in the studied population.

Figure 2 reported the knowledge about the risk of excessive salt on the health of the study population. Results showed that the majority of participants (81\%) have claimed that high salt intake is positively associated with health risks, while just $7 \%$, who have confirmed that there is no relation between excess salt intake and health problems.

Table 3 summarized description of habits use of salt in children and adolescents families. For all

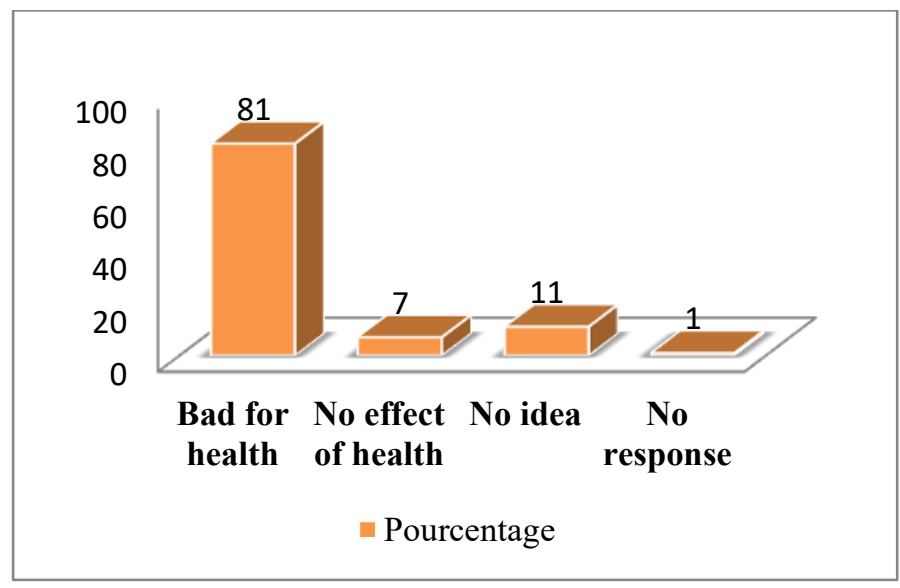

Figure 2: Level of knowledge of participants about the risk of excessive salt on health.

participants, addition of salt to the cooking is a regular habit with a total percentage of $78.9 \%$, while the vast majority $(83.4 \%)$ limits its use at the table during the various meals. Concerning estimation of consumption quantity of salt, about $70 \%$ declare an adequate use, against $10.5 \%$ of participants who admit excess consumption. Regarding iodized salt, about half $(46.6 \%)$ of the study population uses this type of salt. For each variable, a significant difference is shown between sub groups $(\mathrm{p}<0.001)$. 
Table 3: Habits use of salt in the study population

\begin{tabular}{clcccc}
\hline & & Total (\%) & Boys (\%) & Girls (\%) & p-value \\
\hline Addition of salt to the cooking & Never or rarely & 4.5 & 3.1 & 1.5 & $<0.001$ \\
& sometimes & 3.8 & 0.7 & 3 & \\
& Usually & 12.8 & 6.0 & 6.7 & \\
& Always & 78.9 & 41.4 & 37.6 & \\
\hline Addition of salt at the tables & Never or rarely & 83.4 & 41.4 & 42.1 & $<0.001$ \\
& sometimes & 11.3 & 7.5 & 3.7 & \\
& Usually & 1.5 & 0.8 & 0.7 & \\
& Always & 3.8 & 1.5 & 2.3 & \\
\hline Consumption quantity & Much & 10.6 & 6.1 & 4.5 & $<0.001$ \\
& just the right amount & 69.9 & 33.8 & 36.1 & \\
& Little & 15.0 & 8.3 & 6.7 & \\
& Too few & 4.5 & 3 & 1.5 & \\
\hline Use of iodized salt & Yes & 46.6 & 27.1 & 19.5 & $<0.001$ \\
& No & 13.6 & 7.6 & 6 & \\
\hline P-values by Epi-info; & Don't know & 39.8 & 16.5 & 23.3 & \\
\hline
\end{tabular}

Results are expressed on percentages

\section{Discussion}

The habits of using salt among Moroccans is poorly known as well as its health misdeeds on the consumer in the short and long term. In addition, it is already reported by the WHO that salt is very consumed in Morocco [22]. Thus, the main purpose of this study was to determine the salt status in the Moroccan population and to evaluate knowledge of studied subjects about the risk of excessive salt on health.

In the present study, the method of 24 hours dietary recall was applied both to identify different sources that are good sources of salt and to determine the total average quantity. Another questionnaire was also used to evaluate the level of knowledge of health risks associated with high intake and which type (iodized or not) is often used by participants.

Through this study protocol, the total mean of salt intake is $5264.5 \pm 2398.6 \mathrm{mg} /$ day. This result is similar to a study conducted in Australia, showed that the mean $(95 \% \mathrm{CI})$ salt intake estimated from the $24 \mathrm{~h}$ diet recalls was $6.4(6.2,6.7) \mathrm{g} / \mathrm{d}$ for the Lithgow population[30], and other in Switzerland, that the mean of salt was $5.9 \mathrm{~g}(5.3-6.5)$ [31]. On the other hand, a recent study conducted in Costa Rica, the mean daily sodium intake of children and adolescents aged 7 to 18 years was $3.2 \mathrm{~g} / \mathrm{d}$ [32].

Results on the different sources of this nutrient showed that bread and derivatives present the main source counting a total percentage of $61 \%$ and a total mean amount of $370.21 \pm 243.8 \mathrm{~g} /$ day with no statistically significant difference between boys and girls. This bread's daily contribution is remarkably different compared to the average of $300,500 \mathrm{~g} /$ day evaluated previously among the general Moroccan population and that corresponds to a salt intake mean of 8 to $9 \mathrm{~g}$ /day [33]. In this context, numerous studies were conducted. Indeed, in Turkey, it was reported that salt is consumed with an average of $14.8 \pm 5.4$ $\mathrm{g} /$ day and that bread represents the major consumption (34\%) [34]. In Europe, a review evaluated that bread contribution to total salt intake was reported as $25.9 \%$ in Ireland, $24.8 \%$ in Belgium, 24.2\% in France, $19.1 \%$ in Spain, and $19 \%$ in Ukraine [35-36]. In the same term of comparison, bread contribution to daily salt intake, for the Portugal population, was shown to 
range between 20 and 27\% [17]. In South London, a cross-sectional study has been realized, to determine the salt intake of children and adolescents, showed that the mean salt intakes were included between $4.72 \mathrm{~g} / \mathrm{d}$, and $7.55 \mathrm{~g} / \mathrm{d}$ for the 8 to 9 year olds, and 13 to 17 year olds, respectively and that cereal products present the major sources of dietary salt intake (36\%), including bread (Naomi M et al., 2014). From South African research, it was also demonstrated that bread contributes a lot in salt intake [37-38].

Regarding knowledge of the population about health risks of salt intake, findings of this survey showed that the majority of the studied population $(81 \%)$ was very knowledgeable of the contribution of high salt intake in the apparition of many health diseases and problems. Similar results were also found in Tunisian and Australian populations with percentages of $85 \%$ [39] and $88 \%$ respectively [40]. In Ghanaian and South African populations, about 31.3\% of all participants, in a survey in this context, were not aware that the overconsumption of salt could generate a severe health problem [41].

On the other hand, about the half of participants (46.6\%) confirms their usual consumption of iodized salt with no significant difference according to sex. In the same discussion context, a study done in Belgian population in 2014 showed that only $38 \%$ of studied

\section{References}

1. S. K. Ha, M.D. Dietary Salt Intake and Hypertension. Elect \& BP 12:7-18, (2014)

2. B. David, R. Jean, Manual of Nutrition, London, Her Majesty's Stationery Office, p37-38, (1981)

3. He FJ, Macgregor GA, Reducing population salt intake worldwide: From evidence to implementation. Prog CV dis 52:363-382, (2010).

4. World Cancer Research Fund International/American Institute for Cancer Research. Continuous Update Project Report: Diet, Nutrition, Physical Activity and Stomach Cancer. (2016).

5. F.M. Sacks, L.P. Svetkey, W.M. Vollmer, L.J. Appel, G.A. Bray, D. Harsha, E. Obarzanek, P.R. Conlin, E.R. Miller, D.G. Simons-Morton, Effects on blood pressure of reduced dietary sodium and the dietary approaches to stop hypertension (DASH) diet. N. Engl. J. Med., 344, 3-10, (2001)

6. WHO. Global action plan for the prevention and control of non- subjects reported using iodized salt. However, the percentage of people who use this type of salt is also higher in Wallonia (42\%) than in Flanders (34\%) [42]. From the point of view salt use habits, this ingredient is very often added to cooking preparations by a large percentage of our study population $(78.9 \%)$ while its addition to meals is so limited $(83,4 \%$ of non or rare use), this coincides very well with what has been found in most African countries, where salt is commonly added during cooking, and it represent one of major used ingredients [43-44]. Indeed, according to the study on Ghanaians and South Africans already mentioned, it has been reported that the majority of respondents on the survey questions (91\%) frequently add salt to their food during cooking and $74.9 \%$ of them perceive that they consumed just the right amount of salt [41].

This study is therefore part of the national surveys to reveal any misbehavior vis-a-vis the food mode of the Moroccan population to meet the goals set by the Minister of Health. Moreover, a main limitation can be associated with this study and that is related to the degree of true answers to the different questions asked. Therefore, exact evaluation of salt intake using urine samples must be done in future studies to properly estimate the salt status and to support all conclusions and recommendations.

communicable diseases 2013- 2020. (2013).

7. World Health Organization: Reducing salt intake in populations. Report of WHO Forum and Technical Meeting, Paris, (2006)

8. WHO. Salt Reduction. Available online: http://www.who.int/mediacentre/factsheets /fs393/en/ (accessed on 26 May 2017)).

9. J.L. Webster, E.K. Dunford, C. Hawkes, B.C. Neal, Salt reduction initiatives around the world. J Hypertens; 29(6):1043-50. (2011).

10. World Health Organization. Reducing salt intake in populations: report of a WHO forum and technical meeting 5-7 October 2006 Paris, France. France: World Health Organization. (2007)

11. World Health Organization. Guideline: Sodium intake for adults and children, (2012).

12. World Health Organization. Healthy Diet. Available online: http://www.who.int/mediacentre/factsheets /fs394/en/ (2020). 
13. P. Strazzullo, Salt intake, stroke, and cardiovascular disease: meta-analysis of prospective studies. BMJ ; 339:b4567 (2009)

14. J. Stamler, Dietary salt and bood pressure. Ann N Y Acad Sci ;6:122-156.(1993)

15. World Health Organization. Noncommunicable diseases country profiles 2018. Geneva: World Health Organization; Licence: CC BY-NC-SA 3.0 IGO;(2018).

16. A. Ditisheim, E. Muradbegovic, M. Bochud, M. Burnier, A. Pechère-Bertschi. Impact de la consommation de sel sur la santé: les croyances de la population suisse. Rev Med Suisse; 9 : 1613-6.(2013)

17. J.J. Polonia; M.T. Magalhaes; D. Senra; L. Barbosa; J.A. Silva, S.M. Ribeiro, Association of 24-h urinary salt excretion with central haemodynamics and assessment of food categories contributing to salt consumption in Portuguese patients with hypertension. Blood Press. Monit, 18, 303-310.(2013)

18. E. Menyanu, K.E. Charlton, L.J. Ware, J. Russell, R. Biritwum, P. Kowal, Salt Use Behaviours of Ghanaians and South Africans: A Comparative Study of Knowledge, Attitudes and Practices. Nutrients, 9, 939;(2017)

19. N.M. Marrero, F.J. He, P. Whincup, G.A. MacGregor, Salt Intake of Children and Adolescents in South London Consumption Levels and Dietary Sources. Hypertension; 63:1026-1032.(2014)

20. C. Amrouche, O. Berriche, R. Ben Othman, F. Mahjoub, K. Halloumi, F. Chaima, S. Bhouri, A. Gammoudi, H. Jamoussi, Salt intake in a group of Tunisian obeses. Alex J Med (2017)

21. M.M. Zaman, S.R. Choudhury, J. Ahmed, R.K. Khandaker, M.A. Rouf, A. Malik, Salt Intake, Overweight, and High Blood Pressure, With Special Reference to Sex Difference. GLOBAL HEART, 12, 3, (2017)

22. I. Nigrou. L'OMS tire la sonnette d'alarme: Marocains, vous consommez trop, beaucoup trop de sel. Aujourd'hui Le Maroc (2016).

23. World Health Organization, Physical status: the use and interpretation of anthropometry. Report of a WHO expert committee technical, Report Series. 854, (1995).

24. I.H. Rutishauser. Dietary intake measurements. Public Health Nutr., 8, 1100-1107.(2005).

25. A. Uzan, P. Delaveau. The salt content of food: a public health problem. Ann Pharm Fr; 67:291-294. (2009).
26. S.K. Ha, M.D. Dietary Salt Intake and Hypertension. Electrolyte Blood Press 12:7-18, (2014)

27. Y. Erdem, T. Akpolat, Ü. Derici, S. Sengül, S. Ertürk, S. Ulusoy, B. Altun, M. Arici, Dietary Sources of High Sodium Intake in Turkey: SALTURK II. Nutrients, 9, 933; (2017).

28. J. Cade, R. Thompson, V. Burley, D. Warm, Development, validation and utilisation of food-frequency questionnaires - a review. Public Health Nutr, 5:567-587.(2002).

29. P.F. Jacques, S.I. Sulsky, J.A. Sadowski, J.C. Phillips, D. Rush, W.C. Willett, Comparison of micronutrient intake measured by a dietary questionnaire and biochemical indicators of micronutrient status. Am J Clin Nutr, 57:182-189;(1993)

30. J.A. Santos, J. Webster, M.A. Land, V. Flood, J. Chalmers, M. Woodward, B. Neal, K.S. Petersen, Dietary salt intake in the Australian population. Public Health Nutrition, Volume 20 , Issue 11, August 2017,pp. 1887 - 1894. (2017)

31. M.R. Leyvraz, P. Bovet, M. Bochud, B. Genin, M. Russo, M.F. Rossier, R. Tabin, A. Chiolero, Estimation of salt intake and excretion in children in one region of Switzerland: A cross-sectional study. European Journal of Nutrition, 58(7), 2921-2928 (2018).

32. H.N. Rivas, I.H. Schumacher, A.B. Metzler, M.M. Campos, N.C. Saborio, K.B. Aguilar, Salt/Sodium Intake Estimation in Children and Adolescents of Costa Rica. Food and Nutrition Sciences. Vol.11 No.10(2020), Article ID:103612,23 pages (2020).

33. N. Mokhtar, H. Belhadj, D. Kress, A. Zerrari, N. Chaouki, Food-fortification program in Morocco. Food Nutr Bull, 22(4):427-30. (2001)

34. Y. Erdem, T. Akpolat, Ü Derici, S. Şengül, S. Ertürk, S. Ulusoy, B. Altun, M. Arıc1, Dietary Sources of High Sodium Intake in Turkey: SALTURK II, Nutrients, 9,(9), p. E933, (2017)

35. J. Quilez, J.S Salvado, Salt in bread in Europe: Potential benefits of reduction. Nutr, 70, 666-678.(2012)

36. N. Wilson, N. Nghiem, S. Ryan, C. Cleghorn, N. Nair, T. Blakey, Designing low-cost "heart healthy bread": Optimization using linear programing and 15-country comparison. BMC Nutr, 2.(2016)

37. B.C. Nwanguma, C.H. Okorie, Salt (sodium chloride) content of retail samples of Nigerian white bread: Implications for the daily salt intake of normotensive and 
hypertensive adults. J. Hum. Nutr, 26, 488493. (2013)

38. K.E. Charlton, K. Steyn, N.S. Levitt, J.V. Zulu, D. Jonathan, F.J. Veldman, J.H. Nel. Diet and blood pressure in South Africa: Intake of foods containing sodium, potassium, calcium, and magnesium in three ethnic groups. Nutrition. 2005 Jan; 21(1):39-50.(2005)

39. C. Amrouche, O. Berriche, R. Ben Othman, F. Mahjoub, K. Halloumi, F. Chaima, S. Bhouri, A. Gammoudi, H. Jamoussi, Salt intake in a group of Tunisian obeses. Alexandria University Faculty of Medicine.(2017)

40. C.A. Grimes, L.J. Riddell, C.A. Nowson, Consumer knowledge and attitudes to salt intake and labelled salt information. 2009 Elsevier Ltd.(2009)

41. E. Menyanu, K.E. Charlton, L.J. Ware, J. Russell, R. Biritwum, P. Kowal, Salt Use Behaviours of Ghanaians and South Africans: A Comparative Study of
Knowledge, Attitudes and Practices. Nutrients 2017, 9, 939; (2017)

42. K. Gudrun, M. Paulussen, E. Van de Mieroop, M.C. De Wolf, L. Godderis, M. Uytterhoeven, Estimation of salt intake by the Belgian population through analysis of sodium in 24-hour urine samples. Report No.: 2015/ MRG/R/0208 (2015).

43. World Health Organisation. WHO Expert Consultation on Salt as a Vehicle for Fortification; WHO: Geneva, Switzerland, (2007).

44. J.L. Webster, E.K. Dunford, C. Hawkes, B.C. Neal, Salt reduction initiatives around the world. J. Hypertens. 2011, 29, 10431050.(2011). 